\title{
Rapid onset of bronchodilation with formoterol/beclomethasone Modulite and formoterol/budesonide Turbuhaler as compared to formoterol alone in patients with COPD
}

\author{
Mario Cazzola ${ }^{\mathrm{a}, *}$, Franco Pasqua ${ }^{\mathrm{b}}$, Luigi Ferri ${ }^{\mathrm{c}}$, Gianluca Biscione ${ }^{\mathrm{b}}$, Vittorio Cardaci ${ }^{\mathrm{c}}$, \\ Maria Gabriella Matera ${ }^{\mathrm{d}}$ \\ a Unit of Respiratory Clinical Pharmacology, Department of Internal Medicine, University of Rome 'Tor Vergata', Via Montpellier 1, 00133 Rome, Italy \\ ${ }^{\mathrm{b}}$ Rehabilitative Pneumology, San Raffaele Hospital, Velletri (Rome), Italy \\ ${ }^{\mathrm{C}}$ Rehabilitative Pneumology, IRCCS San Raffaele Pisana, Rome, Italy \\ ${ }^{\mathrm{d}}$ Unit of Pharmacology, Department of Experimental Medicine, Second University of Naples, Naples, Italy
}

\section{A R T I C L E I N F O}

\section{Article history:}

Received 19 July 2010

Received in revised form

18 August 2010

Accepted 20 August 2010

\section{Keywords:}

Formoterol

Beclomethasone

Budesonide

COPD

Onset of action

\begin{abstract}
A B S T R A C T
In the present study, we examined whether there is a difference in the onset of bronchodilatation between formoterol/beclomethasone 12/200 $\mu \mathrm{g}$ Modulite and formoterol/budesonide 9/320 $\mu \mathrm{g}$ Turbuhaler in patients with COPD. We enrolled 28 patients with stable COPD. Both formoterol/beclomethasone and formoterol/budesonide elicited a larger mean $\mathrm{FEV}_{1}-\mathrm{AUC}_{0-15 \min }$ than formoterol alone, whereas there was no significant difference between their $\mathrm{FEV}_{1}-\mathrm{AUC}_{0-15 \mathrm{~min}}$. Also the change in $\mathrm{FEV}_{1}$ $15 \mathrm{~min}$ after inhalation of formoterol/beclomethasone combination or formoterol/budesonide combination was greater than that induced by formoterol alone. This study confirms the rapid effect of the inhaled corticosteroid component when combined with formoterol and indicates that the onset of bronchodilation of formoterol/beclomethasone Modulite and formoterol/budesonide Turbuhaler are similar and greater than formoterol alone in patients with COPD.
\end{abstract}

(c) 2010 Elsevier Ltd. All rights reserved.

\section{Introduction}

Preliminary data from a cross-sectional epidemiological study conducted in 17 European countries indicated that symptoms of COPD (breathlessness, phlegm, coughing, wheezing and chest tightness) are almost troublesome in the morning, either immediately upon waking or later in the morning and often interfere with essential activities such as getting out of bed, washing, drying and dressing [1]. These results have serious implications for helping patients manage their condition effectively. Actually, when asked how many days during the preceding week they needed to use their rescue inhaler to be able to perform morning activities, more than half of the patients needed to use their inhaler [2] and it is well known that the fast onset of bronchodilation is an absolute requirement for any inhaled bronchodilator administered on demand [3].

In a previous study, we documented that the addition of formoterol to budesonide accelerates the onset of action of formoterol in patients with COPD and suggested that this finding

\footnotetext{
* Corresponding author

E-mail address: mario.cazzola@uniroma2.it (M. Cazzola).
}

might be explained by actions that can broadly be termed non-genomic [4].

Recently, a hydrofluoroalkane (HFA)-propelled extrafine fixed combination formulation of formoterol/beclomethasone dipropionate $6 / 100 \mu \mathrm{g}$ delivered via pMDI has been developed using the Modulite technology. Each actuation of beclomethasone dipropionate/formoterol 100/6 (nominal dose) delivers $86.4 \mu \mathrm{g}$ of beclomethasone dipropionate and $5 \mu \mathrm{g}$ of formoterol [5]. In patients suffering from moderate to severe asthma, formoterol/beclomethasone dipropionate $12 / 200 \mu \mathrm{g}$ was as rapid as formoterol/budesonide $12 / 400 \mu \mathrm{g}$ in term of onset of bronchodilation [6].

In the present study, we examined whether there is a difference in the onset of bronchodilatation between the two combinations in patients with COPD.

\section{Patients and methods}

Twenty-eight patients with stable moderate to severe COPD were enrolled. Severity was staged according to $\mathrm{FEV}_{1}$ cut-points as suggested by the American Thoracic Society and European Respiratory Society consensus statement [7]. All patients were $>50$ years of age, current or former smokers ( $>10$ pack-years), reporting 
chronic cough with or without sputum production and/or dyspnoea when walking quietly on level ground, or both; they had had no change in symptom severity or treatment in the preceding 4 weeks, had shown no signs of a respiratory tract infection in the month preceding or during the trial, had not been taking oral or inhaled corticosteroids for at least three months and had a best post-bronchodilator $\mathrm{FEV}_{1} / \mathrm{FVC}$ of less than $0.715 \mathrm{~min}$ after salbutamol $200 \mu \mathrm{g}$ [7]. Patients with allergic rhinitis, atopy, and positive skin test or with a total blood eosinophil count over $400 / \mathrm{mm}^{3}$ were excluded. Patients were also excluded if they had any coexisting cardiovascular or lung disorder. Table 1 outlines the baseline characteristics of the population studied.

No oral bronchodilators were permitted for 1 week before and during the study, whereas inhaled short-acting bronchodilator drug and inhaled long-acting bronchodilator agent were not permitted for at least 12 and $24 \mathrm{~h}$ prior to each test, respectively. Consumption of cola drinks, coffee, tea, and smoking in the hours before and during the investigation were also avoided.

The study was performed using a double-blind, double-dummy, randomized, crossover design. It took place over two non-consecutive days. It was carried out according to the rules of the declaration of Helsinki. The institutional review board approved it. All patients provided written informed consent to participate in the study.

Single doses of formoterol/beclomethasone dipropionate (Foster Modulite) 12/200 $(2 \times 6 / 100) \mu \mathrm{g}$ (metered dose), formoterol/budesonide (Symbicort Turbuhaler) $9 / 320(2 \times 4.5 / 160) \mu \mathrm{g}$ (delivered dose) or formoterol (Oxis Turbuhaler) $9 \mu \mathrm{g}$ (delivered dose) were administered.

Measurements of $\mathrm{FEV}_{1}$ were performed before and 3, 6, 10, 15, 20,30 , and $60 \mathrm{~min}$ after inhalation of each treatment. In the first 10 min, single FEV $_{1}$ measurements were recorded, and from $15 \mathrm{~min}$ onwards the best of three recorded $\mathrm{FEV}_{1}$ manoeuvres was recorded.

Considering data of our previous pilot study that documented a difference between formoterol and formoterol/budesonide in FEV $_{1}-\mathrm{AUC}_{0-15 \mathrm{~min}}$ (area under the $\mathrm{FEV}_{1}$ curve from 0 to $15 \mathrm{~min}$ ) of
$300 \mathrm{ml}$ [4], the minimum total required sample size was 50, with minimum required sample size per group of 25 given an $\alpha$-level of 0.05 , an anticipated effect size (Cohen's $d$ ) of 0.725 , and a desired statistical power level of 0.8 . The primary objective of this study was to assess the onset of action of formoterol/beclomethasone compared with that of formoterol/budesonide. The primary variable for this comparison was therefore the average $\mathrm{FEV}_{1}$ during the first $15 \mathrm{~min}\left(\mathrm{FEV}_{1}-\mathrm{AUC}_{0-15 \mathrm{~min}}\right)$. Onset was also compared using the absolute $\mathrm{FEV}_{1}$ measured 15 min after inhalation of study drugs, and time to onset, defined as the first time to $15 \%$ or $200 \mathrm{ml}$ increase in $\mathrm{FEV}_{1}$ over baseline recorded within $60 \mathrm{~min}$ ). Comparisons of baseline characteristics among the two treatments were performed by ANOVA analysis and Fisher's exact test. Analysis of spirometric data was performed using the Student's $t$ test for paired variables. The time-averaged changes in the 60-min period following each drug administration were compared by means of the distribution free crossover analysis [8]. The AUCs were calculated for each patient by means of the trapezoidal rule. Comparisons of AUC values among the three treatments were performed by ANOVA analysis with Bonferroni correction for multiple comparisons. A probability level of $p<0.05$ was considered significant for all tests.

\section{Results}

All patients completed the three-day study. No significant differences occurred between the baseline spirometric values of the three treatment groups for $\mathrm{FEV}_{1}(p=0.2797)$.

Both formoterol/beclomethasone and formoterol/budesonide elicited a larger mean $\mathrm{FEV}_{1}-\mathrm{AUC}_{0-15 \mathrm{~min}}$ than formoterol alone (difference: $0.493 \mathrm{~L}, 95 \% \mathrm{CI}$ : 0.170-0.816, $p<0.01$; and $0.354 \mathrm{~L}, 95 \%$ CI: $0.031-0.677, p<0.05$, respectively), whereas there was no significant difference between their $\mathrm{FEV}_{1}-\mathrm{AUC}_{0-15 \mathrm{~min}}$ (difference: 0.139 L, 95\% CI: $-0.184-0.4619, p>0.5$; Fig. 1). Fig. 2 shows individual changes in $\mathrm{FEV}_{1}-\mathrm{AUC}_{0-15 \mathrm{~min}}$ from those induced by

Table 1

Anthropometric data and pulmonary function of patients.

\begin{tabular}{|c|c|c|c|c|c|c|c|}
\hline Patient & Sex & Age (years) & Height (cm) & Smoking history (pack/year) & $\mathrm{FEV}_{1}(\%$ predicted $)$ & FVC (\% predicted) & $\%$ reversibility \\
\hline 1 & $\mathrm{M}$ & 65 & 165 & 10/daily (63) & 40 & 49 & 16 \\
\hline 2 & M & 71 & 169 & $\operatorname{Ex}(45)$ & 67 & 75 & 13 \\
\hline 3 & M & 67 & 158 & Ex (44) & 63 & 71 & 7 \\
\hline 4 & $\mathrm{~F}$ & 59 & 155 & 30/daily (51) & 38 & 45 & 11 \\
\hline 5 & M & 62 & 164 & 20/daily (66) & 40 & 56 & 6 \\
\hline 6 & M & 68 & 169 & 15/daily (38) & 61 & 67 & 9 \\
\hline 7 & M & 74 & 170 & $\operatorname{Ex}(60)$ & 49 & 72 & 10 \\
\hline 8 & $\mathrm{M}$ & 66 & 163 & 10/daily (35) & 32 & 37 & 14 \\
\hline 9 & $\mathrm{M}$ & 63 & 165 & $\operatorname{Ex}(72)$ & 52 & 58 & 8 \\
\hline 10 & M & 57 & 172 & 15/daily (39) & 59 & 70 & 9 \\
\hline 11 & $\mathrm{M}$ & 64 & 170 & 10/daily (71) & 56 & 62 & 2 \\
\hline 12 & $\mathrm{~F}$ & 59 & 158 & 30/daily (73) & 50 & 59 & 13 \\
\hline 13 & $\mathrm{~F}$ & 70 & 165 & 15/daily (41) & 66 & 76 & 12 \\
\hline 14 & $\mathrm{M}$ & 75 & 162 & 20 daily (80) & 47 & 58 & 16 \\
\hline 15 & $\mathrm{~F}$ & 55 & 165 & 30/daily (49) & 51 & 59 & 8 \\
\hline 16 & $\mathrm{~F}$ & 73 & 168 & $\operatorname{Ex}(70)$ & 51 & 62 & 17 \\
\hline 17 & M & 71 & 163 & Ex (77) & 36 & 41 & 13 \\
\hline 18 & M & 67 & 173 & Ex (85) & 36 & 43 & 3 \\
\hline 19 & M & 63 & 176 & 20/daily (45) & 34 & 37 & 13 \\
\hline 20 & $\mathrm{M}$ & 57 & 166 & 40/daily (79) & 40 & 52 & 10 \\
\hline 21 & M & 64 & 175 & Ex $(120)$ & 48 & 70 & 10 \\
\hline 22 & $\mathrm{~F}$ & 61 & 148 & 20/daily (70) & 31 & 43 & 19 \\
\hline 23 & $\mathrm{~F}$ & 67 & 158 & 20/daily (45) & 71 & 79 & 6 \\
\hline 24 & M & 70 & 164 & $\operatorname{Ex}(70)$ & 62 & 69 & 8 \\
\hline 25 & $\mathrm{~F}$ & 73 & 146 & 10/daily (53) & 32 & 39 & 15 \\
\hline 26 & $\mathrm{M}$ & 60 & 172 & $\operatorname{Ex}(50)$ & 41 & 48 & 2 \\
\hline 27 & M & 66 & 178 & 15/daily (48) & 64 & 75 & 3 \\
\hline 28 & M & 69 & 169 & 20/daily (65) & 52 & 66 & 7 \\
\hline
\end{tabular}




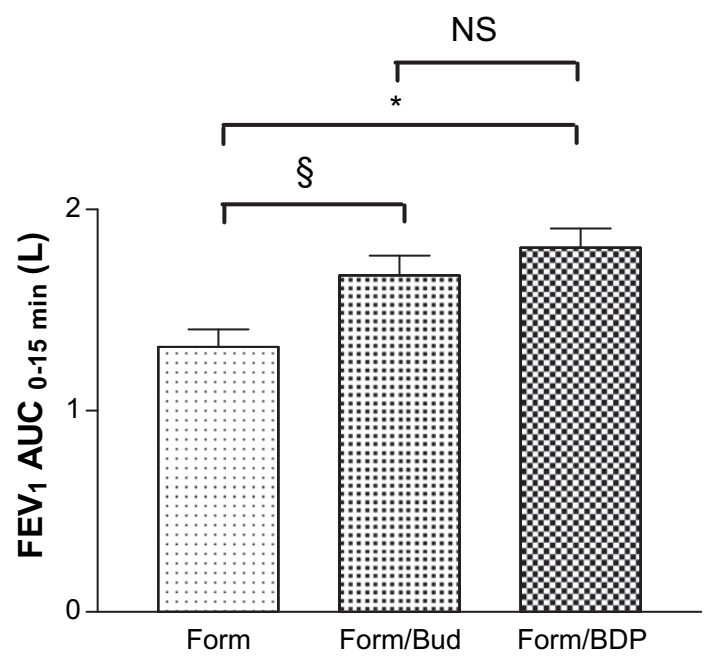

Fig. 1. Mean changes in $\mathrm{FEV}_{1}$ AUC from baseline values to 15 min after inhalation of formoterol (Form) $9 \mu \mathrm{g}$ via Turbuhaler, Form/budesonide (Bud) 9/320 $\mu \mathrm{g}$ via Turbuhaler or Form/beclomethasone dipropionate (BDP) 12/200 $\mu \mathrm{g}$ via Modulite. Bars are SE: $\S p=0.0031,{ }^{*} p<0.0001$, NS, non significant.

formoterol alone elicited by formoterol/budesonide or formoterol/ beclomethasone.

Also the changes in $\mathrm{FEV}_{1} 15$ min after inhalation of formoterol/ beclomethasone combination (0.178 L; 95\% CI: 0.153-0.202) or formoterol/budesonide combination $(0.170 \mathrm{~L} ; 95 \% \mathrm{CI}$ : 0.146-0.194) were greater than that induced by formoterol alone $(0.135 \mathrm{~L} ; 95 \%$ CI: 0.118-0.152) (Fig. 3). A significant difference was found between the improvement after formoterol/beclomethasone and formoterol alone $(0.048 \mathrm{~L} ; 95 \% \mathrm{CI}: 0.020-0.065 ; p=0.0006)$ or formoterol/ budesonide and formoterol alone (0.035 L; 95\% CI: 0.011-0.060; $p=0.0063$ ), whereas there was no significant difference between the improvement after formoterol/beclomethasone and that after formoterol/budesonide ( $p=0.5743$ ).

Thirteen patients out of 28 were unable to achieve a $15 \%$ improvement in $\mathrm{FEV}_{1}$ after formoterol, eleven did not show this change after formoterol/budesonide, and six after formoterol/ beclomethasone. In responsive subjects, formoterol was associated with a rise in $\mathrm{FEV}_{1}$ of at least $15 \%$ after 30 min (95\% CI: 18-43), formoterol/budesonide after $15 \mathrm{~min}$ (95\% CI: 11-18), and formoterol/beclomethasone after $17 \mathrm{~min}$ (95\% CI: 10-24) (Fig. 4). Fourteen out of 28 were unable to achieve a $200 \mathrm{ml}$ improvement in $\mathrm{FEV}_{1}$ after formoterol and formoterol/budesonide and eight did not

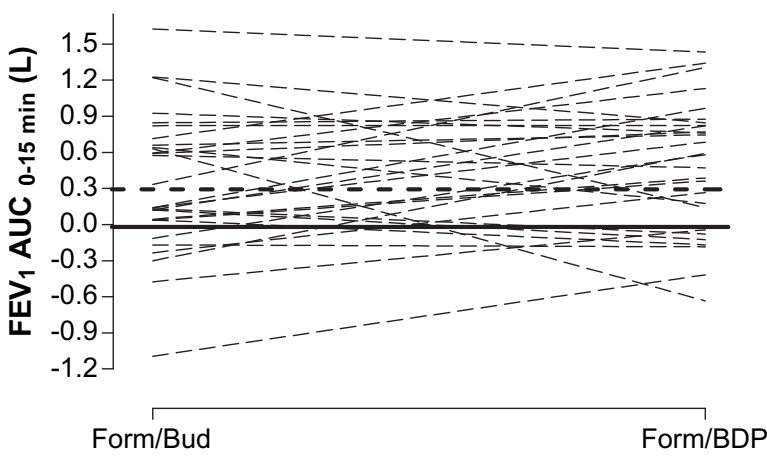

Fig. 2. Individual changes in $\mathrm{FEV}_{1}-\mathrm{AUC}_{0-15 \mathrm{~min}}$ from those induced by formoterol (Form) $9 \mu \mathrm{g}$ via Turbuhaler (solid line) elicited by Form/budesonide (Bud) $9 / 320 \mu \mathrm{g}$ via Turbuhaler or Form/beclomethasone dipropionate (BDP) $12 / 200 \mu \mathrm{g}$ via. Dotted line indicates the minimal importance difference in $\mathrm{FEV}_{1}-\mathrm{AUC}_{0-15 \min }(0.3 \mathrm{~L})$.

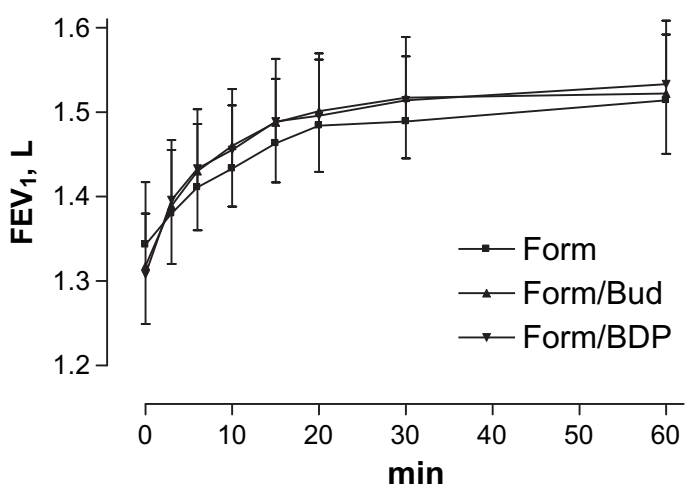

Fig. 3. Mean changes in $\mathrm{FEV}_{1}(\mathrm{~L})$ from baseline value up to 60 min after inhalation of formoterol (Form) $9 \mu \mathrm{g}$ via Turbuhaler, Form/budesonide (Bud) 9/320 $\mu \mathrm{g}$ via Turbuhaler or Form/beclomethasone dipropionate (BDP) 12/200 $\mu \mathrm{g}$ via Modulite. Bars are SE. $p<0.01$ for change of Form vs. baseline at $15 \mathrm{~min}, p<0.001$ for all other changes vs. baseline.

show this change after formoterol/beclomethasone. In responsive patients, formoterol/budesonide induced this increase after $21 \mathrm{~min}$ (95\% CI: 11-31), formoterol/beclomethasone after 19 min (95\% CI: 13-24), and formoterol alone after $37 \mathrm{~min}$ (95\% CI: 25-49) (Fig. 4).

The mean increases in $\mathrm{FEV}_{1}$ from baseline were always significant $(p<0.01$ or $p<0.001)$ with all treatments and higher after formoterol/beclomethasone than budesonide/formoterol or formoterol alone, but differences between combination treatments were not significant $(p>0.05)$ at each explored time point (Fig. 3 ).
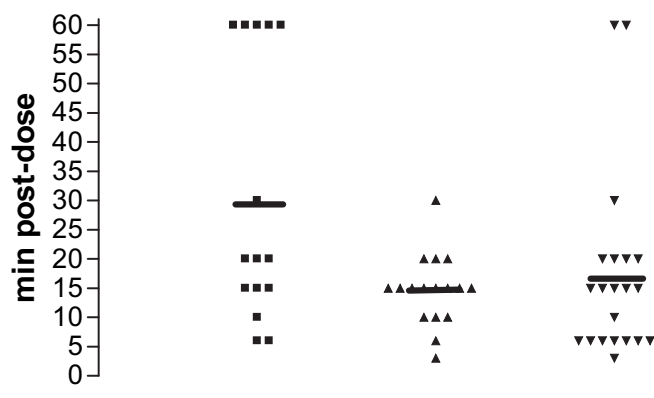

Form

Form+Bud

Form+BDP

$200 \mathrm{ml}$

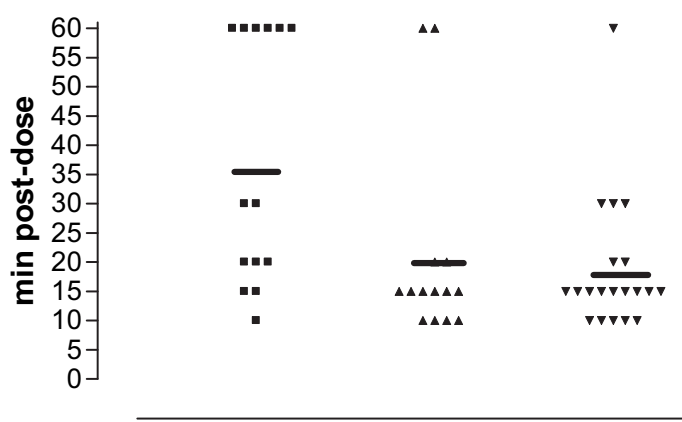

Form $\quad$ Form/Bud Form/BDP

Fig. 4. Patients having an increase in $\mathrm{FEV}_{1}$ of at least $15 \%$ or $200 \mathrm{ml}$ over baseline at different time-points within $60 \mathrm{~min}$ after inhalation of formoterol (Form) $9 \mu \mathrm{g}$ via Turbuhaler, Form/budesonide (Bud) 9/320 $\mu$ g via Turbuhaler or Form/beclomethasone dipropionate (BDP) 12/200 $\mu \mathrm{g}$ via Modulite. 


\section{Discussion}

This study confirms and enlarges the documentation that the addition of budesonide to formoterol influences the fast onset of action of formoterol [4] and, moreover, it shows that also the addition of beclomethasone dipropionate to the same dose of formoterol is able to faster the onset of action of this $\beta_{2}$-agonist. Our results are in keeping with early reports of acute potentiation of rapid bronchodilator actions by corticosteroids $[9,10]$.

It must be mentioned that inhaled corticosteroids alone do not seem to be able to relieve early airway response represented as changes in $\mathrm{FEV}_{1}$. For instance, a rather recent study showed that a single dose of budesonide $(400 \mu \mathrm{g})$ /formoterol $(12 \mu \mathrm{g})$ combination or formoterol alone, but not budesonide alone, given few minutes after airway allergen challenge was able to alleviate early airway response $(0-3 \mathrm{~h})$ [11]. Other studies showed similar results regarding the effect of inhaled corticosteroids [12,13], although there are also several reports that suggest that corticosteroids can induce rapid improvement in pulmonary function [14-16].

On the contrary, there is some evidence that corticosteroids improve $\beta_{2}$-adrenergic bronchodilation. Through delayed transcriptional action on airway cells, corticosteroids could increase $\beta_{2}$-receptor numbers [17] and restore $\beta_{2}$-receptor coupling to $G$ proteins that mediate adenylyl cyclase stimulation [18]. However, it has been known that after administration of corticosteroids, a minimum of $1-2 \mathrm{~h}$ are required for induction of their genomic effects, i.e. appearance of de novo synthesised proteins [19] whereas, in our study it is likely that the facilitating action of budesonide and beclomethasone dipropionate was due to a nongenomic effect. In fact, it appeared almost instantaneously, and certainly within a time frame that precluded significant modifications of gene expression.

Corticosteroid actions that occur within seconds to a few minutes have been referred to as non-genomic or rapid action of corticosteroids and are non-classical actions [20]. These rapid non-genomic effects are assumed to be mediated by three mechanisms: (1) physicochemical interactions with cellular membranes (nonspecific non-genomic effects) [21,22]; (2) cytosolic glucocorticoid receptor (cGCR)-mediated non-genomic effects [23]; and (3) membrane-bound glucocorticoid receptor (mGCR)-mediated nongenomic effects [24]. It is also possible that inhaled corticosteroids increase the tissue concentration of a cationic $\beta_{2}$-agonist, such as formoterol, by inhibiting its local disposal on the one hand and by delaying the vascular clearance by causing vasoconstriction through diminished local disposal of noradrenaline on the other $[25,26]$.

This clinical study does not allow us to determine which of these actions is that underlying the more rapid onset of bronchodilation of formoterol when it is associated with an inhaled corticosteroid, but it confirms that the presence of an inhaled corticosteroid is crucial for having this effect. It is intriguing that topical corticosteroids at very low concentrations show greater non-genomic potency than systemic corticosteroids likely because they are more lipophilic than systemic corticosteroids due to their esterification at position $17 \alpha$ and thus better able to diffuse and intercalate into biological membranes [27]. In any case, it has been documented that some corticosteroids have a larger effect on non-genomic mechanisms than others, although the non-genomic selectivity of corticosteroids may be mechanism-dependent $[28,29]$.

We still do not know whether there are substantial differences in non-genomic effects of budesonide and beclomethasone dipropionate. Nonetheless, it is worthy to be highlighted that apparently there is no difference between beclomethasone $200 \mu \mathrm{g}$ and budesonide $400 \mu \mathrm{g}$ (metered doses) in influencing the onset of bronchodilation of formoterol $12 \mu \mathrm{g}$ (metered dose). However, we must underline that beclomethasone dipropionate has been administered via Modulite and budesonide via Turbuhaler and it is widely accepted that comparisons of inhaled corticosteroids are only scientifically sound when they are given in equivalent doses through comparable delivery devices.

Instead, it is possible that the difference in delivery devices has been important in allowing the same effect with a lower dose of beclomethasone dipropionate. The new fixed beclomethasone dipropionate ( $100 \mu \mathrm{g}$ per each inhalation) and formoterol ( $6 \mu \mathrm{g}$ per each inhalation) combination delivered via Modulite lays in the innovative formulation characterised by an extrafine particle size of drug particles [30]. In fact, both beclomethasone dipropionate and formoterol display a mass median aerodynamic diameter (MMAD) in the range of $1.4-1.5 \mu \mathrm{m}$. Consequently, the amount of drug delivered to the lung, and responsible for the therapeutic effect, is increased whereas the dose of the drug remaining in the upper airways (and potentially responsible for systemic side effects) is reduced. For the same clinical effect, with beclomethasone dipropionate/formoterol HFA extrafine, the beclomethasone dipropionate dose is 2.5-fold lower than the conventional beclomethasone dipropionate chlorofluorocarbon (CFC) product: $400 \mu \mathrm{g}$ beclomethasone dipropionate extrafine was clinically equivalent to $1000 \mu \mathrm{g}$ of the reference beclomethasone dipropionate CFC formulation. This means that a dose of $100 \mu \mathrm{g}$ of beclomethasone dipropionate in extrafine HFA formulation is equivalent, in terms of efficacy, to $250 \mu \mathrm{g}$ of beclomethasone dipropionate in traditional CFC formulation, with a significant lower risk of systemic side effects. It is also important that both components are distributed throughout the lung, including the peripheral airways, which in turn increases the potential for synergistic interaction [31].

In summary, this study confirms the rapid onset of action of formoterol when combined with an inhaled corticosteroid and indicates that the onset of bronchodilation of formoterol/beclomethasone Modulite and formoterol/budesonide Turbuhaler are similar in patients with COPD and greater than formoterol alone. The rapid onset of action may represent a significant benefit for subjects with COPD, especially those with nighttime or early morning symptoms due to reversible bronchospasm.

\section{Conflict of interest}

This paper describes a spontaneous study, which was not supported by any Drug Company.

\section{References}

[1] Partridge MR, Cazzola M, Kessler R, Miravitlles M, Vogelmeier C, Leynaud D, et al. Diurnal variation of symptoms and impact on morning activities in severe COPD: a pan-European cross-sectional study (abstract). Eur Respir J 2009;34:161.

[2] Vogelmeier C, Partridge M, Miravitlles M, Cazzola M, Leynauld D, Ostinelli J, et al. Perception of symptom variability in patients with severe COPD: impact on morning activities and therapeutic behavior (abstract). Am J Respir Crit Care Med 2010;181:A5957.

[3] Friedman M, Della Cioppa G, Kottakis J. Formoterol therapy for chronic obstructive pulmonary disease: a review of the literature. Pharmacotherapy 2002;22:1129-39.

[4] Cazzola M, Santus P, Di Marco F, Carlucci P, Verga M, Matera MG, et al. Onset of action of formoterol/budesonide in single inhaler vs formoterol in patients with COPD. Pulm Pharmacol Ther 2004;17:121-5.

[5] Dhillon S, Keating GM. Beclometasone dipropionate/formoterol: in an HFApropelled pressurised metered-dose inhaler. Drugs 2006;66:1475-83.

[6] Nicolini G, Paggiaro P, Fabbri LM, Papi A. Onset of bronchodilation of extrafine beclomethasone/formoterol combination is equivalent to budesonide/formoterol combination (abstract). Am J Respir Crit Care Med 2008;177:A612.

[7] Celli BR, MacNee W. Standards for the diagnosis and treatment of patients with COPD: a summary of the ATS/ERS position paper. Eur Respir J 2004;23:932-46

[8] Koch GG. The use of nonparametric methods in the statistical analysis of the two period change-over design. Biometrics 1972;28:577-84.

[9] Jeffery J, Garcia J, Avner BP. Corticosteroid potentiation of catecholamine bronchodilator drugs: possible mechanisms of action. Proc West Pharmacol Soc 1979;22:149-53. 
[10] Jeffery JL, Avner BP. Blockade of uptake2: the mechanism of rapid corticosteroid induced potentiation of bronchodilator drugs in tracheal smooth muscle. Proc West Pharmacol Soc 1980;23:355-9.

[11] Duong M, Gauvreau G, Watson R, Obminski G, Strinich T, Evans M, et al. The effects of inhaled budesonide and formoterol in combination and alone when given directly after allergen challenge. J Allergy Clin Immunol 2007;119:322-7.

[12] Kidney JC, Boulet LP, Hargreave FE, Deschesnes F, Swystun VA, O'Byrne PM, et al. Evaluation of single-dose inhaled corticosteroid activity with an allergen challenge model. J Allergy Clin Immunol 1997;100: 65-70.

[13] Wong BJ, Dolovich J, Ramsdale EH, O’Byrne P, Gontovnick L, Denburg JA, et al Formoterol compared with beclomethasone and placebo on allergen-induced asthmatic responses. Am Rev Respir Dis 1992;146:1156-60.

[14] Ketchell RI, Jensen MW, Lumley P, Wright AM, Allenby MI, O'Connor BJ. Rapid effect of inhaled fluticasone propionate on airway responsiveness to adenosine 59-monophosphate in mild asthma. J Allergy Clin Immunol 2002;110:603-6.

[15] Rodrigo GJ. Rapid effects of inhaled corticosteroids in acute asthma: an evidence-based evaluation. Chest 2006;130:1301-11.

[16] Rodrigo G, Rodrigo C. Inhaled flunisolide for acute severe asthma. Am J Respir Crit Care Med 1998;157:698-703.

[17] Mak JC, Nishikawa M, Barnes PJ. Glucocorticosteroids increase $ß_{2}$-adrenergic receptor transcription in human lung. Am J Physiol Lung Cell Mol Physiol 1995;268:L41-6.

[18] Mak JCW, Nishikawa M, Shirasaki H, Miyayasu K, Barnes PJ. Protective effects of a glucocorticoid on down-regulation of pulmonary $ß_{2}$-adrenergic receptors in-vivo. J Clin Invest 1995;96:99-106.

[19] Borski RJ. Nongenomic membrane actions of glucocorticoids in vertebrates. Trends Endocrinol Metab 2000;11:427-36.

[20] Cato AC, Nestl A, Mink S. Rapid actions of steroid receptors in cellular signaling pathways. Sci STKE 2002;138:RE9.
[21] Buttgereit F, Scheffold A. Rapid glucocorticoid effects on immune cells Steroids 2002;67:529-35.

[22] Buttgereit F, Straub HS, Wehling M, Burmester GR. Glucocorticoids in the treatment of rheumatic diseases. Arthritis Rheum 2004;50:3408-17.

[23] Croxtall JD, Choudhury Q, Flower RJ. Glucocorticoids act within minutes to inhibit recruitment of signalling actors to activated EGF receptors through a receptor-dependent, transcription-independent mechanism. Br J Pharmacol 2000;130:289-98.

[24] Bartholome B, Spies CM, Gaber T, Schuchmann S, Berki T, Kunkel D, et al. Membrane glucocorticoid receptors (mGCR) are expressed in normal human peripheral blood mononuclear cells and up-regulated after in nitro stimulation and in patients with rheumatoid arthritis. FASEB J 2004;18:70-80.

[25] Horvath G, Mendes ES, Schmid N, Schmid A, Conner GE, Salathe M, et al. The effect of corticosteroids on the disposal of long-acting $\aleph_{2}$-agonists by airway smooth muscle cells. J Allergy Clin Immunol 2007;120:1103-9.

[26] Kelly L, Kolbe J, Mitzner W, Spannhake EW, Bromberger-Barnea B, Menkes H. Bronchial blood flow affects recovery from constriction in dog lung periphery. J Appl Physiol 1986;60:1954-9.

[27] Naumann L, Feist E, Straub RH, Burmester GR, Buttgereit F. Potencies of topical glucocorticoids to mediate genomic and nongenomic effects on human peripheral blood mononuclear cells. Biochem Pharmacol 2006;71:530-9.

[28] Croxtall JD, van Hal PT, Choudhury Q Gilroy DW, Flower RJ. Different glucocorticoids vary in their genomic and non-genomic mechanism of action in A549 cells. Br J Pharmacol 2002;135:511-9.

[29] Haller J, Mikics E, Makara GB. The effects of non-genomic glucocorticoid mechanisms on bodily functions and the central neural system. A critical evaluation of findings. Front Neuroendocrinol 2008;29:273-91.

[30] Paggiaro P. New pharmacologic perspectives in pneumology: beclomethasone-formoterol extrafine. Open Respir Med J 2009;3:38-42.

[31] De Backer W, Devolder A, Poli G, Acerbi D, Monno R, Herpich C, et al. Lung deposition of BDP/formoterol HFA pMDI in healthy volunteers, asthmatic, and COPD patients. Aerosol Med Pulm Drug Deliv 2010;23:137-48. 